\title{
Programa de Reabilitação Baseado na Comunidade
}

Os Autores

\section{Lessandra da Silva}

Socióloga, jornalista, especialista em educação e teoria da arte e mestre em Administração Pública pela Escola Brasileira de Administração Pública e de Empresas, da Fundação Getulio Vargas (FGV-Ebape).

\section{Valdeir Martins de Faria}

Graduado em Administração, mestrando em Administração Pública da Escola Brasileira de Administração Pública e de Empresas, da Fundação Getulio Vargas (FGV-Ebape). 


\section{PROGRAMA DE REABILITAÇÃO BASEADO NA COMUNIDADE}

O PROGRAMA DE REABILITAÇÃO BASEADO NA COMUNIDADE (PRC), é desenvolvido pela Fundação Municipal Lar Escola Francisco de Paula (FUNLAR), vinculada à Secretaria Municipal de Desenvolvimento Social (SMDS), da Prefeitura do Rio de Janeiro. Teve início em 1994, sob a forma de Projeto, numa parceria entre a FUNLAR e a Associação de Moradores de Vila Progresso, no bairro de Vila Kennedy, na zona oeste. Nessa experiência pioneira, percebeu-se que as pessoas portadoras de deficiência (PPDs) que viviam nessas comunidades precisavam de atendimento, mas não chegavam às instituições por falta de recursos financeiros, dificuldades de locomoção ou pela própria "vergonha das famílias e responsáveis em sair de casa com as PPDs”2. Além disso, os órgãos públicos tinham uma longa fila de espera, poucas vagas para uma crescente demanda, o que dificultava ainda mais a acessibilidade aos serviços de reabilitação. Nesse sentido, a proposta do projeto era a de fazer com que as equipes técnicas se aproximassem mais das comunidades de baixa renda, onde vivia um grande contingente de pessoas portadoras de deficiência. A partir de 1998 houve uma expansão do PRC, para outras áreas do município e uma redefinição em termos de formulação da política social, pois a primeira experiência, em Vila Progresso, apesar de ser precursora do PRC, tinha um caráter eminentemente clínico. Em 1999 é criada a Coordenadoria de Reabilitação Social baseada em Comunidade, sendo o PRC incluído na estrutura organizacional da FUNLAR. Com esse redesenho organizacional, o PRC passa a receber uma verba destinada especificamente ao seu desenvolvimento, o que garante mais autonomia para gerir suas ações. No ano de 2002 o PRC passa a ser considerado como referência Nacional pelo Governo Federal e pela Secretaria de Estado e Assistência Social (SEAS).

O Programa foi pensando para atender às pessoas portadoras de deficiência que moram em comunidades com elevados índices de pobreza e que em geral, encontram-se sem assistência nenhuma, excluídas da sociedade, sem conhecimento de seus direitos. Dessa forma, a principal proposta do PRC é a inclusão social desse segmento da população, que geralmente vive segregado, alijado da vida comunitária, “sem face”, “sem nome”, “sem voz”, ou seja, vivendo uma "invisibilidade" social. Estando muitas vezes submetidos às angustias do isolamento, ao olhar de indiferença que condena aqueles que dele sofrem, as maiores amarras não advém das limitações do corpo, mas sim da apartação social, numa sociedade que ainda dá os primeiros passos num esforço para conceber novas formas de sociabilidade e convivência social.

2 Segundo depoimento de uma supervisora do PRC. 
Historicamente as ações sociais voltadas para as pessoas portadoras de deficiência foram orientadas por pressupostos assistencialistas, paternalistas,e muitas vezes superprotetores e implementadas, na maioria dos casos, por entidades privadas sem fins lucrativos. Essas instituições tiveram um papel importante, no sentido de terem criado uma rede de serviços. Entretanto, essas ações sociais eram fragmentadas e reforçavam a segregação das PPDs, reduzindo as pressões por políticas universalistas que pudessem incorporar esse grupo na rede pública de serviços. A Constituição de 1988 marcou uma profunda mudança na visão das políticas sociais, pois introduziu a Seguridade Social baseada em: Saúde, Previdência e Assistência Social, redesenhando o Estado de direito democrático, garantindo a proteção social e a promoção da cidadania.

Nesse sentido, o PRC fundamenta-se nessa nova concepção de "política social”, baseada numa ampla noção de cidadania na perspectiva da garantia de direitos, que não se limitem apenas a possibilitar a sobrevivência, mas sim que possam inserir a PPDs na vida societária. Isso inclui assegurar a esse grupo possibilidades de inclusão no mundo do trabalho, nas políticas setoriais e no convívio comunitário. Desse modo, o paradigma orientador das ações da FUNLAR baseia-se na inclusão social, que "enfatiza a equiparação de oportunidades, autonomia e independência, busca resgatar a dimensão da pessoa em sua totalidade, imprimindo uma nova concepção à deficiência na ótica das capacidades e potencialidades 3 ”. O programa tem como objetivos principais, a descentralização do atendimento ao portador de deficiência que vive em comunidade de baixa renda, promovendo o envolvimento de suas famílias e da sociedade nas ações voltadas para sua reabilitação, tanto física, quanto social, revertendo a exclusão, por meio de ações interdisciplinares que promovam a ressignificação e melhoria da qualidade de vida. Tem também como objetivos capacitar multiplicadores do Programa nas comunidades e criar oficinas para geração de renda.

\section{O Funcionamento do Programa de Reabilitação Social baseado em Comunidade}

O Programa de Reabilitação Social baseado na Comunidade, iniciou-se com três equipes e atualmente possui 24 equipes, atendendo 283 comunidades carentes do município do Rio de Janeiro. Cada equipe é composta por cinco técnicos (assistente social, fisioterapeuta, fonoaudiólogo, psicólogo e terapeuta ocupacional), que atuam de forma interdisciplinar. Além dessas equipes, o PRC conta com uma equipe formada por professores de educação física, artífices, artistas plásticos e cênicos, que desenvolvem atividades que englobam as várias comunidades atendidas pelo programa. Para cada equipe existe um coordenador e um

3 Queiroga, Elisabete dos Santos. Reabilitação em Comunidade: Uma Política Pública de Inclusão e Desenvolvimento Social. Trabalho 142. In: II Encontro Nacional de Serviço Social e Seguridade - "Seguridade Social é Possível”. 29 de outubro a 2 de novembro de 200l. PUC/RS 
supervisor, este último responsável pelo gerenciamento do trabalho de cerca de cinco equipes nas várias regionais. Em algumas comunidades a equipe é constituída também por um agente comunitário e por agentes multiplicadores. São pessoas da própria localidade, geralmente portadoras de algum tipo de deficiência, e se tornam responsáveis por identificar pessoas portadoras de deficiência e pelo monitoramento das oficinas. O agente comunitário é um cargo remunerado, enquanto o agente multiplicador é voluntário. O trabalho da equipe técnica consiste em primeiramente ir a comunidade procurar as lideranças e buscar uma base local para organizar e desenvolver as atividades. As equipes não possuem, geralmente, uma sede ou espaço físico próprio para atuar nas comunidades. Os técnicos geralmente utilizam espaços cedidos pela própria comunidade, como igrejas, Ongs, associações de moradores, e algumas vezes, instalações da própria SMDS, ou outros órgãos da prefeitura, como as regionais administrativas.

Nesse contato com as lideranças locais é realizado um "mapeamento" da comunidade. Isso consiste num trabalho voltado para conhecer a história local, as manifestações culturais, os hábitos, fazer um levantamento dos recursos públicos existentes, identificar as residências de pessoas portadoras de deficiência física e possíveis parceiros. Posteriormente são realizadas reuniões com a comunidade, a fim de apresentar o Programa, elaborar metas, definir os tipos de oficinas e produtos que a comunidade deseja que sejam desenvolvidos. Em seguida, iniciase o cadastramento das pessoas portadoras de deficiências, por meio de visitas domiciliares, onde é feita uma apresentação do Programa, uma avaliação das condições físicas e de existência da PPDs. Neste processo são avaliados os seguintes aspectos: renda familiar, infraestrutura, aspectos psicológicos, relações entre os familiares entre outros. Os responsáveis pelo PRC acentuam que não focam apenas a necessidade do portador de deficiência, mas também as necessidades da família. Após essa avaliação é feito o encaminhamento para a rede de proteção social, ou seja, verifica-se que tipos de serviços, as famílias necessitam e onde eles podem ser feitos (parcerias com instituições). As famílias identificadas com alto nível de pobreza passam a receber cestas básicas mensais (algumas equipes instituem a freqüência às reuniões de familiares como contrapartida para o recebimento, enquanto outras utilizam simplesmente o critério de necessidade social) por intermédio das Coordenadorias Regionais. As dificuldades sócio-econômicas e as demandas por serviços básicos presentes nessas comunidades, requer na maioria das vezes ações emergenciais que consistem numa multiplicidade de atividades de curto prazo ${ }^{4}$.

4 Por exemplo: compra de filtros d’água, colchões, limpeza dos cômodos, distribuição de cestas básicas, construção de banheiros nas casas, adaptação do espaço físico e mobiliário da residência, além de reabilitação daqueles portadores de deficiência que não tenham condições de se deslocar até o serviço de saúde. Embora o atendimento clínico não seja uma atribuição do PRC, ele é realizado, temporariamente, visando habilitar o PPD a buscar atendimento na rede de serviços de saúde. 


\section{Aspectos Inovadores}

As práticas do Programa de Reabilitação Social Baseado na Comunidade (PCR) são inovadoras, a medida que, promovem uma ruptura com as ações paternalistas e segregacionistas que historicamente orientaram o tratamento com a PPDs. O PRC promoveu uma cisão com o modelo clínico reducionista, que mantinha atividades voltadas para serviços de habilitação/reabilitação desvinculados do processo sócio-pedagógico, cultural, esportivo, recreativo, que possibilitam a participação da família e da comunidade na reabilitação do portador de deficiência.

Desse modo, o PRC inova ao realizar um trabalho "extra muros", como definiu uma entrevistada, ao mudar a concepção de atendimento ao deficiente. Passando, de apenas clínico, para um processo de inclusão social. Inova, considerando o contexto local, ao ir ao encontro dos beneficiários, ao achá-los, já que se trata de um público tão especial e que está bastante “escondido” nos morros do Rio de Janeiro.

“O que há de inovador no programa é o 'como' a gente chega e ouve a família, a abordagem, percebendo suas necessidades e não entregando um pacote pronto... vamos a casa.. Muda até o olhar sobre a família.. Quando trabalhei em uma clinica como Terapeuta Ocupacional, o meu olhar sobre a família era mais acusador... mas quando você vai lá e vê a realidade da família, você consegue compreender um pouco melhor... A gente faz uma atendimento a cada usuário. Percebe-o como uma pessoa e não como um número ${ }^{5}$.”

Assim, a própria descentralização das atividades, o atendimento nas residências, as ações que vão sendo construídas a partir do conhecimento que a equipe vai tendo da realidade específica de cada comunidade, dos valores praticados e das estratégias que buscam no enfrentamento das questões cotidianas, são inovações significativas. Além disso, propõe capacitar indivíduos e comunidades, para questões relativas a legislação, saúde, direitos e deveres do cidadão, ações intersetoriais, estratégias participativas, fortalecendo o capital social, por meio da participação e co-responsabilização da comunidade.

Nesse sentido, o Programa de Reabilitação Social baseado em Comunidade se mostra inovador a medida em que busca habilitar não só a pessoa portadora de deficiência, mas a própria família e a comunidade, desconstruindo a concepção presente no imaginário popular de que essas pessoas são incapazes, pois enfatiza suas potencialidades, não mais segregandoas em lugares ditos “especiais”, mas sim inserindo-as no convívio comunitário. Isso contribui

5 Depoimento de uma supervisora do PRC. 
para minimizar a discriminação e o preconceito na relação da sociedade com as PPDs, passando a uma convivência mais “naturalizada” e espontânea, superando a superproteção ou piedade, atitudes que não contribuem para o desenvolvimento pleno do portador de deficiência. Dessa forma, todas as atividades realizadas, como oficinas e passeios, não são apenas para os PPDs, mas para a comunidade, enfatizando o aspecto da inclusão social.

A própria concepção filosófica do PRC pode ser considerada inovadora a medida em que promove uma reabilitação não mais circunscrita ao “corpo”, ou aos ambientes designados “especiais”, que longe de constituírem-se como espaços privilegiados, confinam o indivíduo num isolamento do mundo real. Ao partir do princípio de que a pessoa portadora de deficiência é um ser íntegro, com direito a desfrutar de plena inclusão societária, na vida econômica, cultural e social, o PRC contribui para a construção de novas relações sociais onde a deficiência seja percebida apenas como uma limitação, mas nunca como uma incapacidade.

Dessa forma, faz-se necessário expor que "cidadania supõe compartilhar os serviços de saúde, oportunidades de educação e capacitação, transporte, habitação, emprego, tempo livre e outros serviços sociais e culturais acessíveis ${ }^{6}$.” Isso amplia não só a concepção de cidadania, como também a responsabilidade dos envolvidos com a pessoa portadora de deficiência, não mais restrita aos profissionais e entidades tradicionalmente habilitadas para tratar desse grupo, mas torna-se um compromisso social do poder público, da família e da sociedade civil.

\section{Recursos e sustentabilidade}

O Programa Reabilitação Social baseado em Comunidade mostra-se eficiente a medida em que promove atividades de reabilitação, considerando-se o atendimento terapêutico, cultural, esportivo, buscando utilizar o ambiente e recursos disponíveis nas comunidades, sem construções especiais ou equipamentos sofisticados. Como afirmou uma supervisora do PRC, "o que acho interessante é que nada é caro, não é nada de outro mundo. O técnico chega na casa e vê o que pode estar sendo melhorado dentro daqueles recursos, melhor utilização do espaço”.

O Programa otimiza a utilização dos recursos a partir do estabelecimento de articulações com as demais políticas públicas, instituições públicas, privadas e comunitárias, que possibilitam a construção de uma rede de serviços capaz de oportunizar o acesso às informações de serviços e uso mais racional dos recursos.

6 Queiroga, Elisabete dos Santos. Reabilitação em Comunidade: Uma Política Pública de Inclusão e Desenvolvimento Social. Trabalho 142. In: II Encontro Nacional de Serviço Social e Seguridade - "Seguridade Social é Possível”. 29 de outubro a 2 de novembro de 200l. PUC/RS 
A promoção de serviços integrados, com o desenvolvimento de políticas públicas intersetoriais, contribui para um gerenciamento mais eficaz das ações implementadas pelo Programa. Para facilitar esse processo foi criado o Centro Integrado de Atenção à Pessoa Portadora de Deficiência - CIAD (que reúne as Secretarias de Saúde, Educação, Esporte e Lazer, Trabalho e Desenvolvimento Social), com a proposta de oferecer serviços de forma integral e integrada. O prédio está localizado no centro do Rio, próximo à Central do Brasil, o que facilita o acesso às suas instalações, pois há diversos transportes públicos nas imediações: metrô, trem e ônibus. A unidade é completamente adaptada à circulação de PPDs, possuindo salas de atendimento, terapia ocupacional, fisioterapia e quadra de esportes. Também pudemos identificar vários portadores de deficiência que trabalham nesse local.

Uma das propostas do programa é instrumentalizar a PPDs e sua família para que conheçam seus direitos de cidadania e possam orientá-los quanto as possibilidades de inserção em creches, escolas e no mercado de trabalho. Tudo isso buscando uma articulação com a rede de serviços e recursos existentes na comunidade ou mais próximos a ela. Essa capacitação e a mobilização de diversos parceiros contribui para dar sustentabilidade ao programa. Isso porque uma das estratégias do PRC para expandir suas ações junto a outras comunidades de baixa renda, consiste em capacitar e envolver a comunidade local, para que estas possam ter autonomia para conduzir as atividades em suas localidades. As equipes técnicas do PRC são itinerantes, e depois de um tempo de permanência nas comunidades, tendo atingido objetivos e metas, a equipe se "retira” da comunidade, indo para outra. Essa saída acontece quando se identifica que após a implantação e consolidação das ações do Programa, a comunidade já está preparada para assumi-lo em grande parte, liberando a equipe técnica para iniciar o trabalho em outro local. Essa "saída” da comunidade também depende da formação dos agentes multiplicadores, moradores locais, voluntários e responsáveis pela continuidade das atividades do PRC em sua comunidade. Este agente multiplicador recebe treinamento e acompanha a equipe do PRC em todas atividades de planejamento e implementação, para que conheça o processo. Passa a ser uma referência da FUNLAR na comunidade. Entretanto, como essa "saída“ não se dá efetivamente, pois apenas a freqüência à comunidade diminui, os técnicos do programa discutem a possibilidade de substituir a expressão “saída da comunidade” pela seguinte designação: “quarta fase do Programa”. Caso a comunidade identifique necessidade do retorno da equipe técnica, as lideranças, os usuários, ou o agente multiplicador acionam os membros do PRC.

Esse momento da "Quarta fase”, ou seja, uma suposta saída da equipe técnica, tem sido um dos grandes desafios enfrentados pelo PRC, pois existe muita dificuldade em identificar 
alguém na comunidade que possa atuar como agente multiplicador, tendo em vista que é um trabalho voluntário e necessita de certas habilidades, como liderança dentro da comunidade. Além disso, a equipe técnica encontra dificuldades em identificar o momento propício para a saída. A interpretação é de que quando o Programa está bastante consolidado, com ampla, efetiva e ativa participação da comunidade, a equipe já possa retirar-se. Entretanto, a saída das comunidades tem se dado mais por causas externas - como violência - do que propriamente por decisão interna. É também difícil construir autonomia da comunidades, tendo em vista as condições de extrema pobreza da maioria, fazendo com que os moradores dessas localidades estejam sempre dependendo muito das equipes, das Organizações não governamentais e do poder público.

Cada comunidade reage diferentemente ao programa, dependendo das condições de existência, da oferta de serviços públicos na área e da influência do narcotráfico. Nos lugares nos quais a equipe técnica já se retirou, a comunidade já identifica onde estão os recursos e sabem para onde devem dirigir-se. Entretanto, a mobilidade dentro das próprias comunidades também é grande. Novos moradores, novos casos de deficiência, enfim, questões que demonstram que mesmo após a "saída”, a equipe técnica precisa retornar algumas vezes. Para isso criaram a "revisita”, ou seja, um retorno da equipe técnica à comunidade, para identificar novos casos de pessoas portadoras de deficiências e verificar a situação das famílias já cadastradas anteriormente. Até para atualizar as informações, porque muitas vezes surgem novos benefícios ao qual essas pessoas têm direito.

O PRC recebe recursos do Tesouro Municipal e da Secretaria de Estado de Ações Sociais (SEAS), do Ministério da Fazenda, constituindo-se como suas principais receitas. Outra forma de captação de recursos se faz por meio da elaboração de projetos que são enviados para instituições fomentadoras, além de recebimentos pontuais, e, em alguns casos permanentes, de doações feitas por vários parceiros. A Coordenadora do PRC enfatiza que a participação do Poder Público num programa como esse é fundamental. Segundo seu relato, a equipe foi convidada pela prefeitura de São Luís, no Maranhão, para explicar o funcionamento do PRC, e, principalmente para esclarecer como se dá a participação financeira do município. Isso porque é comum que programas semelhantes recebam verbas da Secretaria de Estado e Assistência Social (SEAS), mas não, necessariamente, das prefeituras municipais.

Nesse sentido o Orçamento da FUNLAR em 2003 foi de R\$ 1.857.349,60, sendo que destes, R\$ 1.713.506,00 (92,26\%) são oriundos dos cofres municipais e o restante do orçamento, R\$ 143.843,60 (7,74\%), foi complementado pelo repasse feito pelo Fundo Nacional de 
Assistência Social/SEAS. O Orçamento percentual do PRC em relação ao Orçamento total do município foi de $0,02 \%$.

Uma das preocupações do Programa é que o número de atendidos pelo PRC cresce a cada ano. E muitas vezes esse aumento de usuários supera a capacidade do Programa em gerar novos recursos e incrementar a captação. Entre 1994 a 2000 a variação de usuário da FUNLAR (considerando todos os seus Programas, e não apenas o PRC) foi de 1300\%, enquanto a variação de recursos foi de 125\%, aproximadamente. Em 2001 o aporte financeiro da FUNLAR foi de RS 11.610.400,00 (desse valor, 1.890,360 foram destinados ao PRC), o que representa um crescimento de 30\%, sendo que 60,07\% destinados a Serviços, 29,7\% para despesas com Recursos Humanos e 10,46 em material.

Apesar de todas dificuldades, o Programa já tem quase uma década, as descontinuidades administrativas, as mudanças político-partidárias não tem implicado em rupturas na forma como o Programa vem sendo conduzido.

\section{Resultados e Impactos do PRC}

“A esperança não é um número” (...). Porque a vida é inefável7.”

Os resultados do Programa de Reabilitação Social são muitos. Alguns podem ser mensurados por meio de índices numéricos. Entretanto, outros indicadores como promoção da auto-estima, transformação nas relações sociais, ressignificação da vida para essas pessoas portadoras de deficiência, não podem ser traduzidos em números, mas podem ser facilmente observados nos depoimentos dos envolvidos com o Programa. Até porque, segundo relato de uma das supervisoras, o PRC não vê a PPDs como um "número, mas como uma pessoa”. De fato, a vida é inefável e a esperança não se contabiliza em números. Percebe-se nos gestos, no brilho exuberante dos olhos, no sorriso e na satisfação com a qual os portadores de deficiência falam da mudança que o PRC trouxe para suas vidas e como alterou seu próprio comportamento, o de suas famílias e o das próprias comunidades na qual estão inseridos. Libertos das amarras do preconceito,correm com avidez insaciada a descobrir o mundo que flameja e lhes inflama a redescoberta da vida, que agora repousa a confiança na amizade, deixando o gesto e o olhar repreendedor para trás. A saída do isolamento, do confinamento aos muros da própria casa ou da “instituição total”, leva a um refinamento interior que vem da exuberância da possibilidade de experimentar outros caminhos. Mundos diversos. Cores. Sons. Beleza. Seja visitando o Jardim Zoológico, seja participando dos Jogos para PPDs, ou quer seja atuando nas oficinas, a

7 Lispector, Clarice. A descoberta do Mundo. Rio de Janeiro: Editora Rocco, 1999. 
PPDs emerge num cenário em que a sua volta há calor: humano e solar. Há vento. Há possibilidade, onde antes jazia a esperança. Sente-se inebriado: as amarras impostas pelo corpo não mais aprisionam o espírito livre. A vida é inefável, mas os resultados são contundentes.

Nesse sentido, alguns dos resultados que podem ser destacados são as possibilidades que o PRC vem construindo de alterar no imaginário popular as concepções sobre o PPDs, geralmente focadas na suposta incapacidade destes para atividades laborativas e para o próprio convívio societário. Destaca-se também a ampliação e disseminação de informações nas comunidades acerca de medidas de prevenção e dos serviços públicos existentes. Outro resultado importante é o envolvimento de vários parceiros, por meio da construção de uma rede de solidariedade envolvendo o Poder Público, a sociedade civil, as organizações não governamentais e os Conselhos Municipais, na discussão das ações voltadas para a PPDs. A melhoria nos processos de interatividade da Macrofunção de políticas públicas, buscando fortalecer e otimizar a rede de recursos existentes dentro da perspectiva de descentralização e envolvimento da sociedade civil nas políticas públicas também pode ser apontada como um importante resultado. Da mesma forma, o aumento da possibilidade de inserção das PPDs no mercado de trabalho, por meio de capacitação, profissionalização, nas oficinas e cursos promovidos e articulação e convênios com empresas, demonstra a eficácia das ações do programa. Quanto aos resultados quantitativos, o quadro abaixo demonstra o alcance do PRC nesses 9 anos de existência, ou seja, entre 1994 e 2003:

\begin{tabular}{|l|l|}
\hline Comunidades atendidas: 283 & Multiplicadores: 748 \\
\hline População cadastrada: 17.013 & $\begin{array}{l}\text { Atingidos em ações sócio-comunitárias } \\
\text { (arte, esporte, cultura, lazer): 3.400 }\end{array}$ \\
\hline Atendimentos de Reabilitação: 223.341 & Prevenção (Cadastro Gestante de Risco: Bebês de Risco): 417 \\
\hline Visitas domiciliares: 68.000 & Reuniões (usuários, famílias, lideranças, comunidades): 16.926 \\
\hline Parcerias: 1.808 & Oficinas que estão em funcionamento: 62 \\
\hline
\end{tabular}

Um outro fator que indica os resultados que o Programa de Reabilitação Social baseado em Comunidade vem obtendo pode ser expresso por meio do reconhecimento de outras instituições, como a Secretaria de Estado e Assistência Social (SEAS), que considerou o PRC como uma referência nacional; pela Fundação Banco do Brasil, que incluiu o PRC e outros Programas desenvolvidos pela FUNLAR, em seu Banco de Dados de experiências que trazem tecnologias sociais inovadoras e que podem ser reaplicáveis; além disso, o convite de outros municípios para que a equipe explique o funcionamento do PRC, demonstra que o programa tem apresentado resultados importantes e que pode servir como parâmetro para que outras experiências possam ser bem sucedidas. 
A equipe técnica procura mobilizar a comunidade para que sejam feitas avaliações conjuntamente, como forma de transparência no uso dos recursos públicos, e de modo a pensar e refletir sobre os impactos dessas ações, para o estabelecimento de estratégias que sejam construídas coletivamente, envolvendo todos na formulação e, consequentemente, tornando-se co-responsáveis pelo êxito do programa.

\section{Dificuldades enfrentadas pelo Programa de Reabilitação Social baseado em Comunidade}

“Nós nos recusamos a ser como vocês queriam que nós fossemos, nós somos o que somos. É assim que vai ser”.

Ser “diferente” numa sociedade cujo núcleo ideológico da propaganda de mercadorias se assenta num culto ao corpo, implica, na maioria das circunstâncias, a ser privado da admiração coletiva, ser degradado, afastado da possibilidade de tomar decisões sobre a própria vida e, principalmente, da vida social. Um grande desafio que se impõe ao PRC é identificar as estratégias do modelo de exclusão e tentar revertê-lo, sensibilizando a sociedade para essa nova concepção de inclusão social das PPDs. Isso porque a sociedade muitas vezes nem sabe da "existência” dessas pessoas, geralmente segregadas, isoladas, confinadas em suas casas ou instituições sociais. Muitas vezes a própria família esconde o portador de deficiência, tem “vergonha”, ou o que é mais comum, confunde a limitação dos movimentos do corpo, com incapacidade para um convívio social. Mas a principal dor não advém dos limites que a deficiência física impõe ao corpo, mas das amarras tecidas pela marginalização, discriminação e preconceitos que encerram o portador ao confinamento de suas residências, sendo privado do bem estar de uma convivência societária. Esquecem que ser humano é para além do corpo é humanizar-se pela cultura, pelos valores, pelas interações, trocas simbólicas, pelo sonho, pelo desejo, pelo encantamento. Desse modo, as relações sociais transcendem as dificuldades impostas pelas deficiências.

Muitas vezes o preconceito encontra-se na esfera intra-familiar. As vezes, num gesto de carinho e preocupação com o portador de deficiência, os responsáveis assumem uma atitude de super-proteção, o que não contribui para o desenvolvimento das potencialidades dessas pessoas. Dois exemplos ilustram bem essa situação. O primeiro deles, citado por uma das supervisoras do PRC, refere-se a uma PPDs de 35 anos, que não tinha documentos e, dessa forma, não poderia ser inscrito na escola, ou ter direito a qualquer benefício, tendo em vista sua "inexistência social”. A equipe, tentando sensibilizar a mãe do rapaz, ouviu desta o seguinte: "Para quê isso? Ele é só uma criança, não precisa de documentos. Eu cuido muito bem dele. Por que vou mudar isso agora? Ele só precisa de mim”. No segundo exemplo, de acordo com o depoimento da coordenadora, durante uma reunião com a comunidade, a mãe de 
uma moça portadora de deficiência, ao comentar como o PRC teria transformado sua vida, falou: “Ah, esse programa me trouxe 'aborrecimento'. Porque minha filha vivia em casa sozinha, quietinha. Agora essa menina quer sair para as oficinas do PRC, encontrar pessoas, e eu fico preocupada, sem saber onde ela pode estar”. E a coordenadora pode tranqüilizar-se, pois percebeu que o objetivo do programa, ou seja, a inclusão social do portador de deficiência na vida comunitária, estava sendo alcançado ${ }^{8}$.

Para além da esfera familiar, a discriminação aos portadores de deficiência não é menor. Advém, muitas vezes, de instituições públicas e privadas. Portanto, romper com uma cultura institucional e societária que sempre reforçou a segregação e isolamento da PPDs se torna uma tarefa árdua e não menos difícil.

Para mudar essa cultura que impõe uma invisibilidade social ao portador de deficiência foi necessário realizar mudanças estruturais, construindo novas metodologias, capacitando os profissionais de modo que pudessem atuar a partir de uma perspectiva interdisciplinar, conjugando o tratamento clínico e terapêutico a um conjunto de atividades sócio-educativas, profissionalizantes, artísticas, culturais recreativas, onde a PPDs, a família e a comunidade saiam de uma posição passiva e se tornem partícipes, parceiros e co-responsáveis, onde o conhecimento de todos é valorizado e considerado fundamental para a inclusão e reabilitação. Isso traz grandes desafios. Trata-se de um trabalho voltado para a ressignificação da vida da pessoa portadora de deficiência na sociedade.

Dessa forma, uma das estratégias do Programa consiste num amplo processo de sensibilização da sociedade, para as necessidades da pessoa portadora de deficiência. As equipes técnicas perceberam que um importante aliado capaz de facilitar o deslocamento das PPDs seriam os motoristas de ônibus, que precisariam passar por cursos de capacitação para entender e perceber as "diferenças", ou seja, para compreender as dificuldades - nem sempre reconhecidas por estes profissionais - que essas pessoas enfrentam para circular. Nesse sentido, decidiram realizar uma atividade e vivência prática no atendimento às pessoas portadoras de deficiência nos transportes urbanos. De forma lúdica, a equipe vendou os olhos de alguns motoristas, imobilizou braços e pernas de outros e pediu que eles tentassem locomover-se nos ônibus em movimento. Sucumbidos por um cansaço prévio (que advém da limitação dos movimentos do corpo) da vida que por alguns momentos terão que viver, os

\footnotetext{
Um outro exemplo significativo, foi relatado por uma Terapeuta Ocupacional do PRC: “Nós temos alguns exemplos, como as duas Graças, viviam 'enfurnadas' em casa... elas têm uma deficiência mental... foram para as oficinas e se conheceram, agora as duas vivem juntas.. e uma delas a mãe achava que não tinha habilidade para nada .. e na oficina ela se tornou a melhor na confecção de canudinhos de papelão... ela faz o melhor canudinho... ou seja, ela é uma parte importante do processo de produção.. se não tiver um canudo com a qualidade do dela, o produto não sai com qualidade.. e ela sabe disso...”
} 
motoristas passam por essa experiência, sensibilizam-se e reconhecem as dificuldades de acesso que as PPDS tem, não de forma piedosa, mas realista. A experiência fez com que a maioria tomasse consciência das dificuldades. Além disso, a equipe técnica do PRC elaborou uma cartilha de orientação para auxiliar os motoristas no atendimento das pessoas portadoras de necessidades especiais, chamado “Transporte Eficiente”. Além dessa sensibilização com os motoristas, as equipes costumam utilizar a mesma dinâmica nas ruas do município do Rio de Janeiro, com grande concentração e movimentação de pessoas, para chamar a atenção para as dificuldades que as pessoas portadoras de deficiência encontram para circular nos espaços públicos. De acordo com o relato de supervisora, o que se pretende é "construir um espaço para todos. Onde possamos conviver com todas as diferenças, com as necessidades de cada um”.

Outra dificuldade encontrada é a inserção das PPDs nas escolas, pois em geral, essas instituições alegam não possuir habilitação especial para receber esses alunos. O depoimento da coordenadora do PRC retrata essa situação:

Quando nós chegamos à comunidade, nós encontramos o portador de deficiência lá, escondidinho dentro de casa. Nós começamos a fazer com que ele descubra esse mundo. Desde fazer uma pipa na rua, fazer uma festa na rua, até encaminhá-los para órgãos de atendimentos, escolas, etc. (...) Mas nós tivemos que mudar os dois lados. Por que quando chegávamos para fazer a matrícula na escola tudo ia bem até a instituição saber que a pessoa era portadora de deficiência. Aí não tinha mais a vaga. Essas coisas aconteciam freqüentemente. Então, tivemos que fazer sensibilização e capacitação dos professores nas escolas. Hoje nós já não precisamos mais intermediar a vaga, pois o próprio portador de deficiência vai lá e é atendido.... isso hoje é fruto de uma trabalho de parceria com a Secretaria de Educação.

Como um dos objetivos do Programa é justamente garantir o direito à cidadania, incentivar a inclusão, a participação social e a manutenção dos laços familiares, a equipe técnica considera fundamental a inserção em escolas universalistas e não nas ditas "especiais”. O relato da supervisora do PRC é claro: "Isso rompe com o que estávamos dizendo: eu não posso receber esse aluno porque não tenho professor 'especial'. E esse usuário, que mora lá em cima do morro, com dificuldades ímpares, que situações especiais ele encontra lá? E ele desce, eles estão acostumados a enfrentar as barreiras arquitetônicas e barreiras sociais mesmo. Especiais todos nós somos, como ser humanos por excelência, por formação. A escola hoje recebe o portador, coloca apenas uma rampinha. Essa inclusão nas salas regulares é fundamental. Para minimizar o problema a equipe técnica do PRC promove cursos de capacitação para os profissionais e 
educadores que trabalham em escolas da comunidade, como forma de facilitar o convívio com a PPDs.

Dessa forma, uma das dificuldades que o Programa enfrentou foi a relação inter-institucional. E continua tendo problemas. Porque o trabalho desenvolvido pelo PRC depende da articulação com outras secretarias, principalmente as de Saúde e Educação. E muitas vezes não existem vagas. Tem-se uma rede de proteção social, mas esta não consegue atender ao grande número de solicitações. E o que mais agrava a situação é o fato do tipo de atendimento a um portador de deficiência muitas vezes ter que ser feito com urgência, pois a demora pode causar uma patologia sem possibilidade de reversão.

Um dos objetivos do PRC é a geração de renda para os portadores de deficiências. Nesse sentido, uma das importantes formas de melhoria da qualidade de vida das PPDs é sua inserção no mercado de trabalho ${ }^{\mathbf{~}}$. Mas isso se torna extremamente difícil, a medida em que a taxa de desemprego é alta e pelo fato de que este grupo aparece no imaginário popular como “incapacitado”, inclusive, pelas dificuldades de locomoção. Assim, além de superar as próprias barreiras impostas pela deficiência, esse segmento precisa superar o preconceito, na maioria das vezes implícito, de parcela da população. As pessoas portadoras de deficiência já encontram dificuldades de inserção no mercado de trabalho. Mas o público do PRC isso se torna ainda mais difícil, pois são pessoas com baixo nível de escolaridade, que vivem em comunidades com uma configuração geográfica que não facilita o seu deslocamento.

Apesar da existência da Lei Federal 8.213 de 1991, que estabelece que as empresas com mais de 100 funcionários reservem 2\% a 5\% das vagas a PPDs e da Lei Estadual 2816, de 17 de junho de 1999, que prevê que um mínimo de 5\% da totalidade das vagas a empresas contratadas para prestação de serviços em órgãos públicos de Entidades da Administração Pública do Município deve ser destinada a esse segmento, os resultados ainda são insatisfatórios.

Nesse sentido, o PRC entende que uma das formas de ressignificação da vida da PPDs se dá pelo trabalho. Dessa forma, criou diversas oficinas (cerâmica, pátina, bijuteria, cestaria, costura, crochê, cartonagem, silk-screen, confecção de bonecos, hortas) e a escolha de uma dessas depende do interesse e das potencialidades de cada comunidade. A oficina não serve

\footnotetext{
Pesquisas, segundo trabalho de Denise Souza, indicam que a pessoa portadora de deficiência tem desempenho igual ou superior a seus colegas de trabalho. Empresas como Microsoft, Johnson \& Johnson, IBM, Caterpillar e Charles Schwab no ano de 1999 foram as que mais empregaram PPDs. In: Oficinas: ressignificando vidas pelo trabalho. II Encontro Nacional de Serviço Social e Seguridade. "Seguridade Social é Possível”. 29 de outubro a 2 de novembro de 200l. PUC/RS.
} 
apenas como terapia ocupacional, mas tem como objetivo incrementar a renda familiar. Busca-se fazer com que os integrantes das oficinas saibam todo o processo de produção. Uma importante parceria foi feita com o SEBRAE, que capacitou os participantes para a gestão, de modo que estes estivessem habilitados a definir o preço e negociar formas de comercialização do produto. E existe sempre ênfase na qualidade, pois o objetivo é a venda, é a possibilidade de competir no mercado, de modo a gerar renda para os portadores de deficiência e suas famílias. Entretanto, a maioria das oficinas ainda não é auto-sustentável, dependendo de doações.

As oficinas são compostas por pessoas de ambos os sexos, de idades e deficiências variadas (visual, mental, auditiva, múltiplas). São inclusivas, pois não se destinam somente aos portadores de deficiência, constituindo-se num espaço capaz de desmistificar preconceitos e barreiras de uma vivência cidadã. As oficinas tem esse caráter sócio-pedagógico, inclusivo, de produção, de desenvolvimento de habilidades, gerenciamento, criatividade e persistência, para garantir acabamento com qualidade.

Outra forma de buscar integração ao mercado de trabalho se deu por meio da criação de um Banco de dados de pessoas portadoras de deficiência com condições de inserção no mercado de trabalho; cursos profissionalizantes e articulação e convênios com instituições públicas, privadas e cooperativas. Foram realizados convênios com as seguintes empresas, entre outras: Rio Luz, Rio Águas, Mercados Mundial, Spoletto e Petrobras, Coca-Cola, Fininvest, Bob’s e Rio Ônibus.

Uma ação de cooperação entre a FUNLAR e a Cooperativa Especial de Trabalho e Produção dos Portadores de deficiência Usuários da FUNLAR - COOPLAR também vem contribuindo para essa inserção de PPDs no mercado de trabalho. Em gestão conjunto, foi possível firmar um convênio com a Rio Luz que abriu 20 vagas. Nesse convênio, foi possível a COOPLAR receber recursos do FAT que serão aplicados na formação profissional.

\section{Considerações finais}

A inclusão social e a cidadania são os principais objetivos do PRC. Nesse sentido, a inserção do PPDs na vida familiar e sócio-comunitária e a compreensão das condições de exclusão dos PPDs são fatores básicos para dimensionar a relevância social da proposta. O Programa possibilitou a elevação da auto-estima do portador de deficiência, como o depoimento de um deles: "eu antes me sentia um inútil para a sociedade. Agora sei que posso dar minha contribuição e me sinto mais valorizado". 
Nesse sentido, um dos pontos fortes do Programa é a concepção ampliada de cidadania, entendida como direito à vida comunitária em todas as dimensões, econômica, social, no desfrute do tempo livre e na possibilidade de criação de espaços de sociabilidade que possam ser compartilhados por “todos”, independente de suas “diferenças”. A cidadania se constrói com o envolvimento da participação da população na elaboração e implementação de políticas públicas. Ao envolver diversos atores nesse processo, não apenas as pessoas portadoras de deficiência e seus familiares, mas também a comunidade e instituições que geralmente não se sentiam preparadas para atuar com esse público, o Programa rompe com a concepção tradicional de políticas voltadas para a reabilitação social, que segregavam esse grupo, mantendo-os numa completa invisibilidade social.

Antes do programa, em 1993, o trabalho voltado para os deficientes era apenas clínico, com a criação do PRC o atendimento toma outro formato: a proposta agora é encontrar essas pessoas, as mais excluídas, e lhes apresentar o mundo, os seus direitos, os seus valores, as suas potencialidades. Destaca-se como inovação por ser uma forma de trabalho inédita no país, já que a única referência que tinham de algo semelhante era em uma cidade do Canadá. Nesse sentido, isso também pode ser apresentado como um ponto forte, a concepção filosófica que norteia o atendimento ao portador de deficiência.

A forma como os recursos são gerenciados também é muito interessante. O PRC funciona como um agenciador de recursos públicos existentes, a medida em que identifica as necessidades e tenta encaminhá-las para serviços de instituições públicas ou privadas, buscando parcerias que possam atender as necessidades.

Nesse sentido, cabe destacar que uma das estratégias do Programa consiste justamente na criação de uma ampla rede de parcerias, como forma de sensibilização, envolvimento, mobilização, e finalmente, a inclusão dos portadores de deficiência na vida comunitária. Destaca-se que o PRC só pode funcionar com essa lógica da Macrofunção. Não é um programa que se sustenta isoladamente. Funciona como um articulador, buscando integrar as políticas públicas, para usar com mais eficiência os recursos. Assim, mantém um permanente diálogo com órgãos públicos e da sociedade civil.

Outro aspecto que pode ser apontado como ponto forte é a forma como são estabelecidos os diálogos e como o programa altera a relação entre os beneficiários, o poder público e a sociedade civil. As equipes do PRC atuam em comunidades com alto índice de violência, mas nunca tiveram problemas com as facções criminosas que dominam o local, pois o trabalho da equipe é reconhecido como fundamental para a comunidade. Também estabelecem contato com empresas, como a Petrobras e vários hotéis, onde buscam espaço para divulgação e venda dos produtos confeccionados nas oficinas de arte. Contam ainda com o apoio de várias ONGs, 
associações, secretarias, instituições públicas. Nesse jogo de parcerias, a grande contribuição é a apresentação e discussão do problema, a partir da qual as instituições passam a reconhecer o deficiente como um cidadão comum, e não só porque a lei manda. E o mesmo passa a sentirse como cidadão.

Apesar de grandes méritos, O PRC apresenta problemas: falta de sistematização de dados que permitam um acompanhamento mais eficaz para monitorar os resultados e apresentar dados mensuráveis que possam também servir para orientar futuras ações. Entretanto, isso está sendo realizado, com a informatização dos dados, por meio de uma parceria feita com a FIOCRUZ, que vem desenvolvendo uma avaliação do Programa, com a construção de quadros e indicadores que permitam um maior controle das ações, da eficácia e efetividade do programa.

Ainda com relação às limitações, há a carência de veículos para o transporte das equipes, a violência nas comunidades, as barreiras impostas por outros órgãos do governo municipal, como as secretarias. Foi relatado que há dificuldades, principalmente nos atendimentos médicos e acesso às escolas para os deficientes, mesmo havendo parcerias com as secretarias responsáveis pela prestação deste serviço. Esse tipo de queixa demonstra que há fragilidade nesses relacionamentos. Mas, o grande mérito do Programa consiste em ampliar as possibilidades da convivência social para esta população, por meio de rotinas festivas, passeios aos parques, jogos, recreação, lazer, trabalho. 


\section{ANEXOS}

A visita ao Programa de Reabilitação baseado na Comunidade aconteceu durante os dias 14 e 15 de agosto de 2003. No primeiro dia tivemos contato com as gestoras do Programa, a fim de conhecer o seu funcionamento. No segundo dia pudemos visitar uma comunidade onde o Programa foi implementado, a Rocinha, considerada a maior “favela” da América Latina. Lá tivemos contato com a equipe técnica responsável pela área, conversamos com beneficiários do Programa, visitamos várias residências e pudemos participar de uma oficina. Conversamos com diversos atores envolvidos com o PRC, diretamente ou indiretamente. Forneceram-nos um número significativo de documentos e informações acerca do Programa, incluindo fotos. Acompanhamos, durante o segundo dia, a rotina de trabalho da equipe técnica e pudemos verificar os procedimentos que utilizam e constatar o envolvimento com a comunidade.

\section{Entrevistados}

Foram ouvidos cerca de 25 depoimentos. Entre estes, destacam-se os relatos de pessoas portadoras de deficiência, liderança comunitária e membros da equipe técnica.

\section{Documentos Examinados}

Primeiro Relatório do Projeto de Avaliação Qualitativa do PRC - Fundação Oswaldo Cruz/Escola Nacional de Saúde Pública. Abril de 2003;

Prefeitura do Rio - Balanço Social FUNLAR 2002;

Casas Dia;

QUEIROGA, Elisabete dos Santos. Reabilitação em Comunidade: Uma Política Pública de Inclusão e Desenvolvimento Social. Trabalho 142. In: II Encontro Nacional de Serviço Social e Seguridade - "Seguridade Social é Possível". 29 de outubro a 2 de novembro de 2001. PUC/RS;

SOUZA, Denise. n: Oficinas: ressignificando vidas pelo trabalho. II Encontro Nacional de Serviço Social e Seguridade. "Seguridade Social é Possível”. 29 de outubro a 2 de novembro de 200l. PUC/RS; 